\title{
Evaluation of Plasma-Assisted Noninvasive Surgery (PANIS) as a New Technique for Sublimating Large Benign Conjunctival Nevus with Amniotic Membrane Transplantation (AMT); A Clinical Case Report
}

Farhad Nejat ( $\sim$ fanejat@yahoo.com )

Semnan University of Medical Sciences and Health Services https://orcid.org/0000-0002-9614-0926

Khosrow Jadidi

Semnan University of Medical Sciences and Health Services

Shima Eghtedari

Semnan University of Medical Sciences and Health Services

Maryam Moradi

Iran University of Medical Sciences

Nazanin Sadat Nabavi

Semnan University of Medical Sciences and Health Services

\section{Research Article}

Keywords: Conjunctival nevi, PANIS method, AMT, Ablation, Plasma medicine

Posted Date: November 30th, 2021

DOI: https://doi.org/10.21203/rs.3.rs-1110209/v1

License: (c) (1) This work is licensed under a Creative Commons Attribution 4.0 International License. Read Full License 


\section{Abstract}

Background: conjunctival nevi are benign ocular lesions with a low risk of malignant transformation to melanoma. Due to cosmetic reasons patients usually consider surgical removal options. In this case report, we are presenting a new approach using plasma-assisted noninvasive surgery (PANIS) with amniotic membrane transplantation (AMT) to sublimate the nevus border and fuse the AMT with the remaining conjunctiva.

Case presentation: A 33-year-old man with a history of large conjunctival nevus in his left eye, that its benignity was proved by an expert ophthalmologist through years of examination, has visited our center in September 2020. Plasma spots were used to sublimate the nevus border and fuse AMT with the conjunctiva. The patient was discharged fully satisfied without any complications and no recurrences were seen in a year of follow-up. Visual parameters were not significantly changed while the Ocular Surface Disease Index (OSDI) was reduced dramatically.

Conclusion: Conjunctival nevi removal using the PANIS method with AMT is a safe, minimally invasive, and inexpensive therapeutic option. Plasma spots are suitable for AMT adhesion to the remaining conjunctiva after the nevus removal.

\section{Background}

Nevus of the conjunctiva presents as a benign pigmented tumorous lesion of the ocular surface. The bulbar conjunctiva was the most commonly affected area. They can be congenital, melanocytic, epithelial, or stromal lesions. While they are the most common benign lesions of the ocular surface, melanomas are rare and malignant. Due to the comparable clinical features between melanomas and other pigmented nevi, biopsies of such lesions usually should be taken to determine if the lesion is benign or malignant. Cosmetic reasons are also an indication for complete excisional removal (1-4).

Conjunctival nevi are most common in young adulthood and variable in size, color, and location. White people are more prone to develop conjunctival nevus but gender has not been associated. They are classified into compound (most common, nevi cells in the epithelium and subepithelial connective tissue), junctional (contiguous nests of round/spindle melanocytes near basal cell region with oval nuclei), subepithelial (nevus cells only in subepithelial connective tissue, no pigment, bland nuclei), and blue nevi. During puberty, these nevi are more noticeable due to the hormonal changes and they can get larger, darker, or even transformed to malignant forms (4-6).

Even most of the conjunctival nevi are benign and the risk for malignant transformation is less than $1 \%$, but about 21 to $25 \%$ of malignant melanomas are in association with preexisting conjunctival nevus (6). Patients with conjunctival nevi, prefer surgical removal and ophthalmology follow-up due to cosmetic reasons and also cancer prevention $(7,8)$. 
Plasma is the fourth state of matter has been introduced as a new noninvasive method to treat different disorders such as wound healing, cancer field, and also ophthalmology (9). Using plasma-assisted noninvasive surgery (PANIS) is a promising technique in various ocular surface disorders. Conjunctival cyst, conjunctivochalasis, pinguecula, and dry eye treatment with temporary punctal occlusion have been discussed with the PANIS method in our previous articles (10-15). Currently, the PANIS method has been used to remove pterygium with amniotic membrane transplantation (AMT) as a new approach (16).

In this case report, we are presenting a new therapeutic technique using the PANIS method for sublimating conjunctival nevus border and fusing AMT with the remaining conjunctiva.

\section{Case Presentation}

A 33-year-old man with a history of left large conjunctival nevus has visited the Vision Health ophthalmic center in Tehran, Iran between September 2020 and September 2021. His nevus was 7mm in length and 3 $\mathrm{mm}$ in diameter and due to the large containing area and its cosmetic effect, it has decreased our patient self-esteem (Figure 1). According to the history and physical examination by different expert ophthalmologists, the nevus has not changed in size, color, or shape in times, and benignity factors such as the presence of cystic lesions, no bleeding, and lack of arteries were determined (17). Our patient has not had any other symptoms such as blurred vision, irritability, tearing, and itching.

This study has been approved by the ethics committee of Semnan University of Medical Sciences (IR.SEMUMS.REC.1398.321), adheres to the Declaration of Helsinki and informed consent was taken.

Slit-lamp examination was performed before the surgery and nevus size was also measured. The white hand-piece of plasma generator device (Plexr, GMV s.r.l Grottaferrata, Italy) with 0.7-watt power was used in this study (Table 1). Plasma contain charged particles that ionize the air between the needle and tissue, causing tissue sublimation without any thermal damage to the bare sclera. After the tissue removal, plasma spots were used for AMT fusion to the targeted area. 
Table 1

Technical features of Plexr device

\begin{tabular}{|c|c|}
\hline Parameters & Values \\
\hline Working gas & Air \\
\hline \multirow[t]{2}{*}{ Power supply } & Docking station $=24 \mathrm{~V}$ \\
\hline & Handpieces: embedded inductive charger $=5 \mathrm{~V}$ \\
\hline \multicolumn{2}{|l|}{ Handpieces: } \\
\hline Max output & $\leq 2 \mathrm{~W}$ \\
\hline Max working voltage & $\leq 1,3 \mathrm{kVPP}$ \\
\hline Output frequency & $(70-80) \mathrm{kHz}$ \\
\hline \multicolumn{2}{|l|}{ Handpiece types: } \\
\hline White & $\begin{array}{l}\text { V peak to peak }=500 \mathrm{~V}, \text { Power }=0.7 \mathrm{~W}, \text { Frequency }= \\
75 \mathrm{kHz}\end{array}$ \\
\hline Green & $V$ peak to peak $=600 \mathrm{~V}$, Power $=2 \mathrm{~W}$, Frequency $=75 \mathrm{kHz}$ \\
\hline Red & $V$ peak to peak $=700 \mathrm{~V}$, Power $=2 \mathrm{~W}$, Frequency $=75 \mathrm{kHz}$ \\
\hline $\begin{array}{l}\text { Maximum absorbed power (Docking } \\
\text { station) }\end{array}$ & $120 W$ \\
\hline Applicator electrode & Stainless steel sterile disposable needle \\
\hline Risk classification of the device & Ilb (Medium-high risk) \\
\hline
\end{tabular}

\section{Surgical technique}

The surgery was performed in the operating room by Dr. Farhad Nejat. For anesthesia, topical tetracaine 0.5\% (Sina Darou, Tehran, Iran) was used, three times with 5 minutes interval. The patient was placed behind the slit-lamp and the procedure begins with the Plexr device to sublimate and cut the nevus plus 1.5-2 mm safe margin. After the complete nevus removal, AMT was placed in the bare sclera and plasma spots were used to fuse the AMT to the conjunctiva (see additional file 1). In this procedure, plasma spots were used for sublimating and also fusing. We have not used any suture string or fibrin glue for fusion during the surgery.

After surgery, Ciprofloxacin 0.3\% (Sina Darou, Tehran, Iran) was prescribed every six hours and betamethasone $0.1 \%$ (Sina Darou, Tehran, Iran) every four hours for the first week. The betamethasone eye drop was tapered off for one month. 
The patient has not had any complications during and after the surgery and he has the utmost satisfaction. Pathology and biopsy findings of the nevus have consisted of a piece of strip-shaped grayish tissue measuring $8 \mathrm{~mm}$ in length and $5 \mathrm{~mm}$ in diameter, suggestive for irritated compound nevus.

Clinical follow-ups after 2 days, a week, a month, and a year were performed and the change in color and shape of the nevus are shown in Figure 2. The surgery had no significant effect on the measured visual parameters while it had lowered the Ocular Surface Disease Index (OSDI) (Table 2). Patient satisfaction was measured using 2 following questions; would you consider this surgery for your other eye if it will happen, and would you suggest this procedure to your family members if they had it. Our patient response was positive to both questions. We suggested our patient to visit the ophthalmologist annually.

Table 2

Visual parameters before and after the surgery

\begin{tabular}{|lcccc|}
\hline & UCVA & BCVA & IOP & OSDI \\
\hline Pre-surgery & 0.8 & 0.9 & 12 & 43.7 \\
\hline Post-surgery & 0.8 & 0.9 & 14 & 14.6 \\
\hline $\begin{array}{l}\text { Abbreviations: UCVA= Uncorrected visual acuity, } \\
\text { pressure, OSDI= Ocular Surface Disease Index }\end{array}$ & & Best corrected visual acuity, IOP= Intra ocular \\
\hline
\end{tabular}

\section{Discussion}

Conjunctival nevi are melanocytic lesions that can be congenital and occur within the 6 months of life, or acquired and appear within the first two decades of life. These lesions are usually benign and malignant transformation is rare. For these lesions, close monitoring with photography by an expert ophthalmologist is recommended. Diagnosis is made by slit-lamp examination and sometimes pathology and biopsy (18-20). Even the incidence rate of growing malignant melanoma on preexisting conjunctival nevi is rare but, the patients usually prefer surgical removal. Cosmetic reasons are the first and most common reason for nevi removal surgery based on different studies. Ocular surface irritation was another reason for surgical options according to the patients (21). Similar to other studies, cosmetic reasons have caused our patient low self-esteem due to the nevus appearance, therefore; surgical option was his preferable choice (22).

Surgical intervention is necessary when the lesion is growing or its color is changing. The only way to discover the pathology is surgical removal followed by biopsy results. One of the surgical techniques is a full-thickness excision with a surgical microscope under general anesthesia. In this procedure, the nevus is removed along with a healthy margin and then closed with Vicryl 8-0 suture strings. Conjunctival edema, congestion, conjunctival hypertrophy, and also scaring were the post-surgery complications (23).

Another surgical option in large conjunctival nevi removal is using AMT to reconstruct the site of surgery after conjunctival resection. There are several advantages to using an amniotic membrane (AM). They 
are rich sources of stem cells that can help conjunctival epithelialization and healing process, maintain a normal conjunctival cosmetic appearance, and also reduce inflammation, immune rejection, vascularization, scarring, and pain after the surgery $(24,25)$.

Argon laser photoablation of conjunctival nevi is a safe, inexpensive, and fast alternative to surgery. This method is used especially when classical surgery is impossible due to the large size of the nevus. Argon laser ablation is a simple procedure without intraoperative hemorrhage. The recurrence rate is lower than the classical surgery. Against its simplicity, argon laser can destroy a primary malignant lesion without the ability to do histopathology testing for definite diagnosis (26-28). Post-operative inflammation, choroidal and ciliary body detachment, and subretinal neovascularization are other complications following argon laser ablation (29-31).

Pattern Scan Laser (PASCAL) photocoagulation is an alternative method for conjunctival nevi removal. In this method, collateral injuries were reduced due to the pulse duration reduction. Reduction in ocular pain during the procedure was another advantage of this method rather than argon laser ablation. After longterm follow-ups, there was no sign of recurrence or scaring. Similar to argon laser ablation, the PASCAL method also cannot have the histopathological confirmation of the tissue (32).

Recently, plasma radiofrequency ablation has been used to remove various nevi in different parts of the body such as skin and around the eye and its safety has been discovered $(33,34)$. Based on our previous studies on the PANIS method and its efficacy, it has shown that this method can be a minimally invasive technique for various ocular surface disorders (10-15). Therefore; in this case report, we are presenting a new approach for conjunctival nevus ablation using the PANIS method with AMT in a young adult. We did not use any fibrin glue or suture strings in this procedure and plasma spots were used for cutting, sublimating, and also fusing the AM to the conjunctiva. There was no sign of recurrence in 1 year of follow-up and the patient's OSDI was reduced after the surgery.

\section{Conclusion}

The PANIS method application with AMT in conjunctival nevus ablation is a safe, minimally invasive, sutureless with short learning curve, and inexpensive technique. Plasma spots are suitable for AMT adhesion to the remaining conjunctiva after the nevus removal. There were no postoperative complications immediately after the surgery and also in one year of follow-up.

\section{Abbreviations}

\section{PANIS}

plasma-assisted noninvasive surgery/ AMT:amniotic membrane transplantation/ OSDI:Ocular Surface Disease Index/ UCVA:Uncorrected visual acuity/ BCVA:Best corrected visual acuity/ IOP:Intra ocular pressure. 


\section{Declarations}

Ethics approval and consent to participate: This study has been approved by the ethics committee of Semnan University of Medical Sciences (IR.SEMUMS.REC.1398.321), adheres to the Declaration of Helsinki and informed consent was taken.

Consent for publication: The authors confirm that written consent has been obtained from the patient for submission and publication. A copy of the patient consent for publication is available for review by the editor of the journal.

Availability of data and materials: Not applicable

Competing interests: The authors declare that they have no competing interests.

Funding: This study was approved and supported by the Semnan University of Medical Sciences.

Authors' contributions: F.N conceived of the presented idea, developed the theory and performed the computations. M.M wrote the manuscript with support from F.N and SH.E. Kh.J and N.N helped supervise the project.

Acknowledgments: Not applicable

Our manuscript adheres to CARE guidelines and an official completed CARE checklist is attached as an additional file.

\section{References}

1. Furdova A, Pesko K, Strmen P, Kobzova M (2007) Conjunctival nevus and melanoma. Bratisl Lek Listy 108(7):287-291

2. Maschi C, Caujolle JP, Liolios I, Costet C (2013) [Benign conjunctival tumors]. J Fr Ophtalmol 36(9):796-802

3. Röck T, Bösmüller HC, Bartz-Schmidt KU, Röck D (2018) Surgical management of a conjunctival nevus with amniotic membrane transplantation. Int Med Case Rep J 11:161-165

4. Novais GA, Fernandes BF, Belfort RN, Castiglione E, Cheema DP, Burnier MN (2010) Jr. Incidence of melanocytic lesions of the conjunctiva in a review of 10675 ophthalmic specimens. Int J Surg Pathol 18(1):60-63

5. Albreiki DH, Gilberg SM, Farmer JP (2012) Conjunctival malignant melanoma: A rare variant and review of important diagnostic and therapeutic considerations. Saudi J Ophthalmol 26(2):151-156

6. Thiagalingam S, Johnson MM, Colby KA, Zembowicz A (2008) Juvenile conjunctival nevus: clinicopathologic analysis of 33 cases. Am J Surg Pathol 32(3):399-406

7. Colarossi C, Milazzo M, Paglierani M, Massi D, Memeo L, Canzonieri V (2013) A juvenile case of conjunctival atypical nevus. Diagn Pathol 8:64 
8. Jovanovic P, Mihajlovic M, Djordjevic-Jocic J, Vlajkovic S, Cekic S, Stefanovic V (2013) Ocular melanoma: an overview of the current status. Int J Clin Exp Pathol 6(7):1230-1244

9. Laroussi M (2018) Plasma Medicine: A Brief Introduction.Plasma. ; 1(1)

10. Farhad Nejat KJ, Shima Eghtedari N-S, Nabavi (2021). Evaluation of efficacy of plasma assisted noninvasive surgery (PANIS) as a novel approach for temporary punctal occlusion: a clinical case series,. SCIREA Journal of Clinical Medicine Vol 6, No 6, pp 421 - 4322021

11. Jadidi K, Nabavi N-S, Nejat MA, Aghamollaei H, Adnani S-Y, Nejat B et al (2021) Evaluation of plasma assisted noninvasive surgery (PANIS) as a new approach for the treatment of conjunctivochalasis; a clinical case series. Expert Review of Ophthalmology 16(3):225-230

12. Nejat F, Jadidi K, Amoli FA, Bagheri S, Aghamollaei H, Nejat M-A et al (2021) Safety evaluation of the atmospheric low-temperature plasma (ALTP) on the conjunctiva: an animal study and histopathological findings; 6-month follow-up. BMC Ophthalmol 21(1):333

13. Nejat F, Jadidi K, Nejat MA, Nabavi N-S, Adnani S-Y, Eghtedari S (2021) A Novel Approach to Treatment of Pinguecula Using Atmospheric Low-temperature Plasma: A Clinical Case Series. American Journal of Clinical and Experimental Medicine 9:148-152

14. Nejat F, Jadidi K, Pirhadi S, Adnani SY, Nabavi NS, Nejat MA (2020) A Novel Approach to Treatment of Conjunctival Cyst Ablation Using Atmospheric Low-Temperature Plasma. Clin Ophthalmol 14:2525-2532

15. Nejat F, Nabavi N-S, Nejat M-A, Aghamollaei H, Jadidi K (2019) Safety evaluation of the plasma on ocular surface tissue: An animal study and histopathological findings. Clinical Plasma Medicine 14:100084

16. Nejat F, Jadidi K, Eghtedari S, Nabavi NS, Moradi M (2021) Evaluation of Plasma-Assisted Noninvasive Surgery (PANIS) As a New Approach for Pterygium Removal with Amniotic Membrane Transplantation (AMT); a Clinical Case Series. International Journal of Innovative Research in Medical Science 6(11):808-813

17. Tanaka M, Okisaka S, Nakayasu K, Kanai A (1995) [Clinical importance of inclusion cysts of nevi in bulbar conjunctiva]. Nippon Ganka Gakkai zasshi 99(2):190-194

18. Shields CL, Fasiuddin AF, Mashayekhi A, Shields JA (2004) Conjunctival nevi: clinical features and natural course in 410 consecutive patients. Arch Ophthalmol 122(2):167-175

19. Negretti GS, Roelofs KA, Damato B, Sagoo M, Parvizi S, Cohen VML (2021) The natural history of conjunctival naevi in children and adolescents. Eye (Lond) 35(9):2579-2584

20. Levecq L, De Potter P, Jamart J (2010) Conjunctival nevi clinical features and therapeutic outcomes. Ophthalmology 117(1):35-40

21. Alkatan HM, Al-Arfaj KM, Maktabi A (2010) Conjunctival nevi: Clinical and histopathologic features in a Saudi population. Ann Saudi Med 30(4):306-312

22. Dimacali VG, Liu YC, Ong HS, Ting DSJ, Mehta JS (2021) Femtosecond laser-assisted excision of conjunctival melanocytic lesions: Cosmetic and long-term outcomes. Clin Exp Ophthalmol 49(3):312-315 
23. Rakusiewicz K, Kanigowska K, Grajkowska W, Hautz W (2019) Surgical treatment of conjunctival nevi in pediatric patients. Klinika Oczna / Acta Ophthalmologica Polonica 121(1):29-33

24. Röck TBH, Bartz-Schmidt KU, Röck D (Surgical management of a conjunctival nevus with amniotic membrane transplantation. Int Med Case Rep J 2018);11:161-165. 2018

25. Tomita M, Goto H, Muramatsu R, Usui M (2006) Treatment of large conjunctival nevus by resection and reconstruction using amniotic membrane. Graefes Arch Clin Exp Ophthalmol 244(6):761-764

26. Alsharif AM, Al-Gehedan SM, Alasbali T, Alkuraya HS, Lotfy NM, Khandekar R (2016) Argon Laser Photoablation for Treating Benign Pigmented Conjunctival Nevi. Middle East Afr J Ophthalmol 23(3):247-249

27. Kwon JW, Jeoung JW, Kim TI, Lee JH, Wee WR (2006) Argon laser photoablation of conjunctival pigmented nevus. Am J Ophthalmol 141(2):383-386

28. Shin KH, Hwang JH, Kwon JW (2013) Argon laser photoablation of superficial conjunctival nevus: results of a 3-year study. Am J Ophthalmol 155(5):823-828

29. Er H, Doganay S, Turkoz Y, Cekmen M, Daglioglu MC, Gunduz A et al (2000) The levels of cytokines and nitric oxide in rabbit vitreous humor after retinal laser photocoagulation. Ophthalmic Surg Lasers 31(6):479-483

30. Yuki T, Kimura Y, Nanbu S, Kishi S, Shimizu K (1997) Ciliary body and choroidal detachment after laser photocoagulation for diabetic retinopathy. A high-frequency ultrasound study. Ophthalmology 104(8):1259-1264

31. Varley MP, Frank E, Purnell EW (1988) Subretinal neovascularization after focal argon laser for diabetic macular edema. Ophthalmology 95(5):567-573

32. Park YM, Lee JE, Lee JS (2016) Efficacy of Pattern Scan Laser photocoagulation for superficial conjunctival nevi ablation. Lasers Med Sci 31(5):1037-1039

33. Di Brizzi EV, Russo T, Agozzino M, Argenziano G, Giorgio CM, Calabrese G et al (2019) Plasma radiofrequency ablation for treatment of benign skin lesions: Clinical and reflectance confocal microscopy outcomes. Skin Res Technol 25(6):773-776

34. Zheng X, He S, Li Q, Chen P, Han K, Wang M et al (2018) Successful treatment of verrucous epidermal nevus with fractional micro-plasma radio-frequency technology and photodynamic therapy. $\mathrm{J}$ Cosmet Laser Ther 20(6):357-359

\section{Figures}




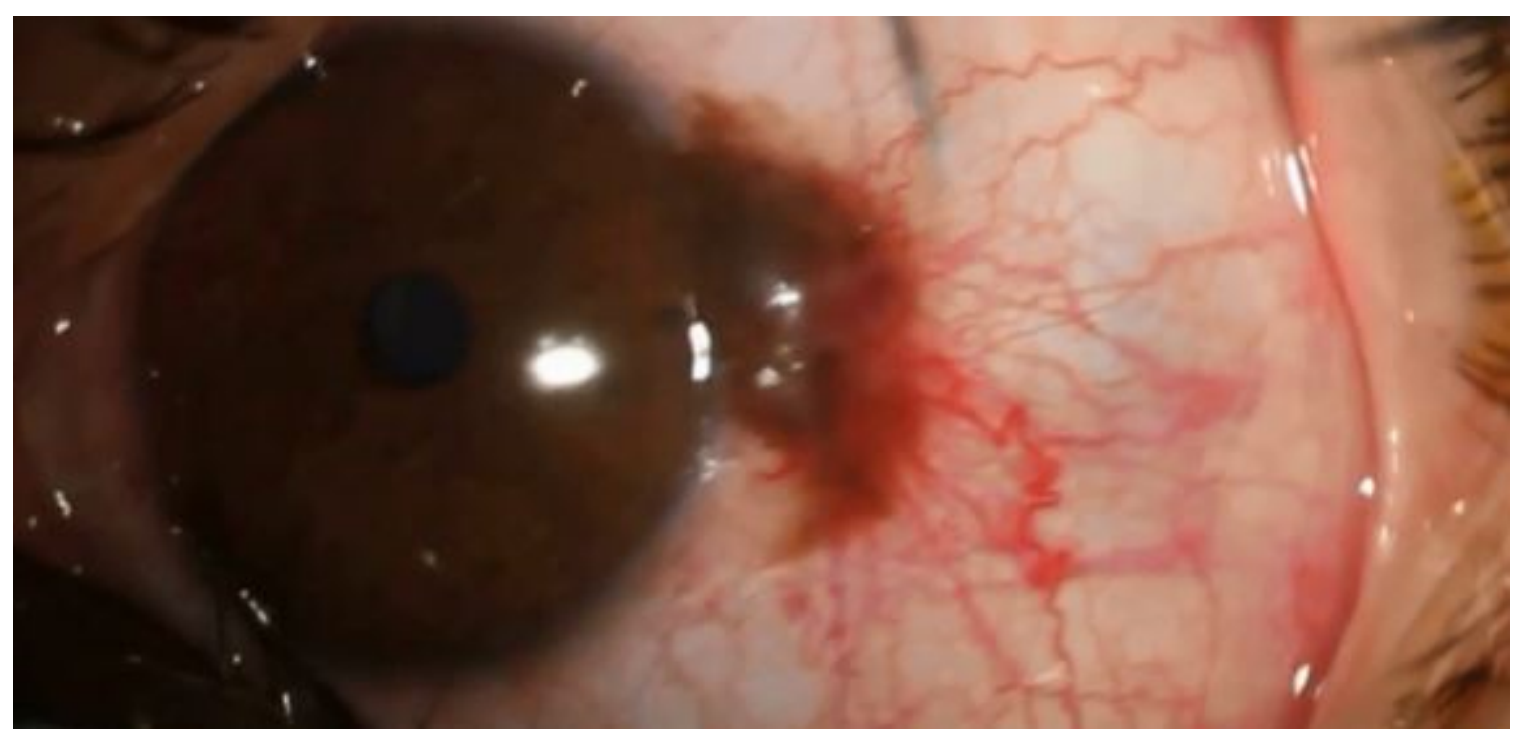

Figure 1

Patient conjunctival nevus before the surgery 

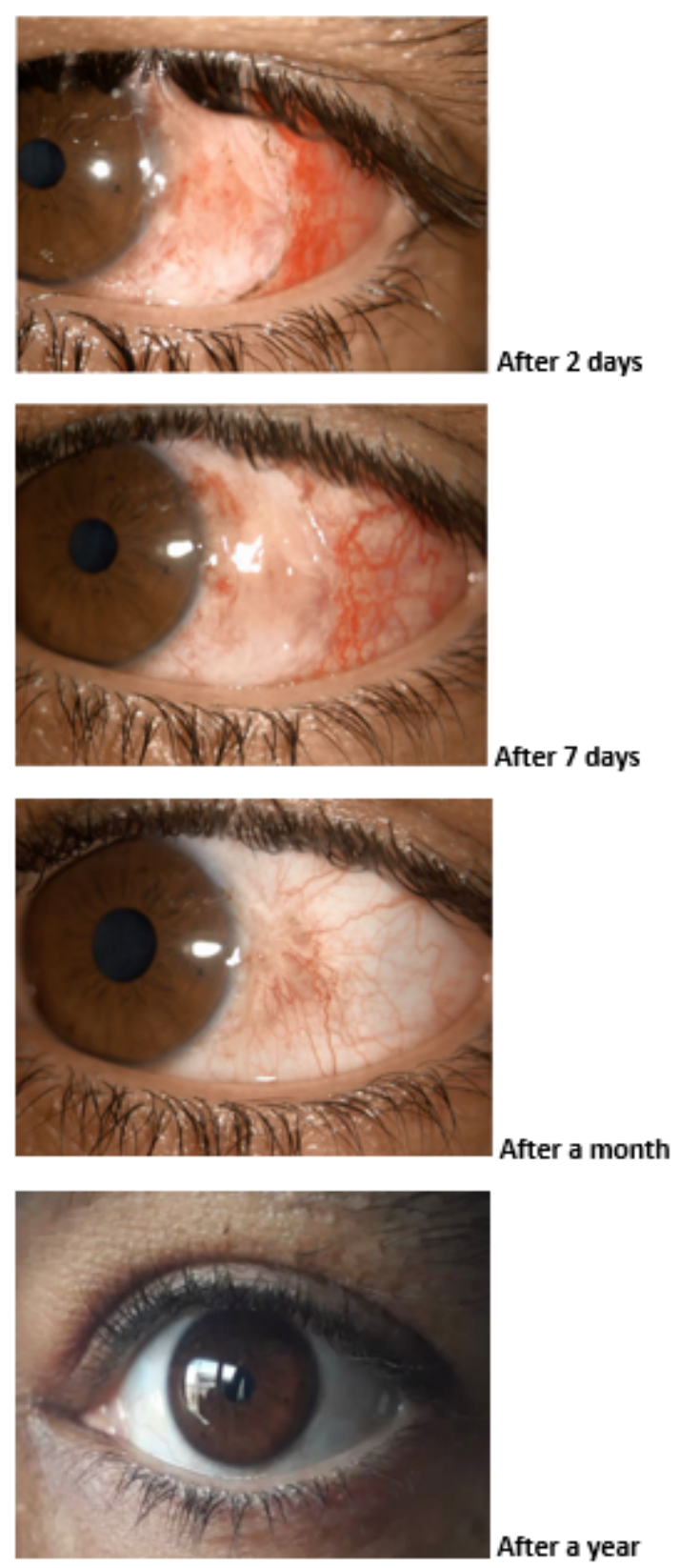

Figure 2

Patient conjunctival nevus 2 days, a week, a month, and a year after the surgery

\section{Supplementary Files}

This is a list of supplementary files associated with this preprint. Click to download.

- nevuswithAMTsurgicaltechnique.mp4 